\title{
Magnetic resonance imaging in the prone position and the diagnosis of tethered spinal cord
}

\author{
Melissa M. Stamates, MD, ${ }^{1}$ David M. Frim, MD, PhD, ${ }^{1}$ Carina W. Yang, MD, ${ }^{2}$ \\ Gregory L. Katzman, MD, ${ }^{2}$ and Saad Ali, MD² \\ 'Section of Neurosurgery, and 2Department of Radiology, The University of Chicago, Illinois
}

\begin{abstract}
OBJECTIVE Tethered cord syndrome (TCS) is a neurosurgical disorder with varied clinical manifestations believed to result from vascular compromise due to stretch forces on the spinal cord. Conventional supine MRI findings may include a low-lying conus medullaris, thickened or fat-infiltrated filum terminale, or lipoma; however, imaging sensitivity and specificity for tethered cord can be low. The purpose of this study was to evaluate the utility of prone MRI in the diagnosis of tethered and retethered spinal cord.
\end{abstract}

\begin{abstract}
METHODS Medical records were reviewed in 41 patients who underwent surgical release of tethered cord and in whom preoperative prone MRI sequences were available. Patients were divided into Group 1 (new TCS diagnosis) and Group 2 (recurrent TCS after previous untethering). Absolute conus ventral motion and motion as a percentage of canal width between supine and prone positions was measured in these 2 groups via sagittal T2-weighted sequences; these groups were compared with 30 consecutive patients (Group 3) who were classified as the normal control group.

RESULTS The mean ventral motion was as follows: Group 1 (absolute: $0.5 \pm 0.5 \mathrm{~mm}$ [range 0-2.4 mm]; canal percentage: $3.7 \% \pm 3.9 \%$ [range 0\%-16.3\%]); Group 2 (absolute: $0.4 \pm 0.7 \mathrm{~mm}$ [range 0-2.6 mm]; canal percentage: $2.2 \% \pm$ $3.7 \%$ [range 0\%-14.0\%]); and Group 3 (absolute: $3.4 \pm 1.3 \mathrm{~mm}$ [range $1.4-5.6 \mathrm{~mm}$ ]; canal percentage: $22.0 \% \pm 7.2 \%$ [range $10.5 \%-36.1 \%$ ]). Whereas $38 / 41$ surgically treated patients with TCS had diminished $(<10 \%$ canal width) ventral motion on preoperative MRI, $30 / 30$ controls had $>10 \%$ canal width motion. Sensitivity and specificity were thereby calculated as $92.7 \%$ and $100 \%$, respectively.
\end{abstract}

CONCLUSIONS In the present series, prone imaging is found to be a sensitive and specific tool, and the authors believe it may have a role as supportive evidence in the diagnosis of tethered and retethered spinal cord.

https://thejns.org/doi/abs/10.3171/2017.3.PEDS16596

KEY WORDS tethered cord; prone MRI; spine

$\mathrm{T}$ ETHERED cord syndrome (TCS) is a neurosurgical disorder with clinical manifestations believed to result from stretch forces on the spinal cord that result in injury. ${ }^{6}$ Presenting signs and symptoms are variable and include scoliosis, back pain, gait difficulty, leg weakness, or bowel and bladder dysfunction. This disorder is often associated with distal spinal structural abnormalities, most commonly a thickened or fat-infiltrated filum terminale, with or without a low-lying conus medullaris. ${ }^{12}$ Patients with this disorder present with varying levels of disability. Even with treatment, patients are at risk for recurrence, which is described clinically or radiographically as "retethering." The rates of symptomatic retethering vary substantially in the literature and depend primarily on the type of lesion. Fatty filum sectioning, for example, is associated with relatively low rates of retethering $(7 \%-9 \%) .^{20,23}$ In 1 series, complex etiologies such as lipomyelomeningocele and prior myelomeningocele repair were associated with a $34 \%$ rate of retethering following primary repair, compared with $7 \%$ in cases of noncomplex etiologies such as fatty filum and split cord malformation. ${ }^{17}$ Along with variable incidence, the time course to presentation also varies widely, from $<1$ year to decades after an initial untethering procedure. ${ }^{14,23}$ Prompt diagnosis and treatment of

ABBREVIATIONS TCS $=$ tethered cord syndrome.

ACCOMPANYING EDITORIAL See pp 1-3. DOI: 10.3171/2017.3.PEDS17126.

SUBMITTED November 7, 2016. ACCEPTED March 9, 2017.

INCLUDE WHEN CITING Published online October 27, 2017; DOI: 10.3171/2017.3.PEDS16596. 
TCS can lead to preserved function over longer periods of time. However, complaints such as back pain or subtle decreases in gait or bladder function are nonspecific and can be difficult to objectively assess clinically. In these cases, supplemental tests are usually needed to reach a confident diagnosis.

Current diagnostic tools for TCS include bladder urodynamic assessment, ${ }^{10}$ electromyography,,$^{15}$ and MRI. Objective assessment by conventional supine MRI remains a challenge, particularly for retethering, because these patients typically continue to display a low-lying conus, despite adequate initial untethering. Furthermore, cord tethering symptoms may occur despite a normal-appearing conus position and filum terminale, as part of an entity called "occult" TCS. ${ }^{12}$ Magnetic resonance sequences with prone imaging, first described in 1996 by Vernet et al., ${ }^{21}$ can show ventral conus movement related to gravity in patients with normal spinal cords ${ }^{22}$ and can imply laxity of the spinal cord; however, results have been mixed in the available literature when assessing cord motion in patients with cord tethering and retethering. ${ }^{13,18,21}$ Despite the limitations of MRI, it remains preferred as a noninvasive technique for the evaluation of spinal pathology and in supporting the diagnosis of TCS.

At our institution, we routinely obtain prone MRI sequences when TCS is suspected clinically. The purpose of the present study is to evaluate, in a larger sample than is available in the current literature, the utility of prone imaging for assessing ventral conus motion in patients with suspected TCS, and for assessing spinal cord retethering after initial surgical repair.

\section{Methods}

This study was performed in accordance with guidelines set forth by the institutional review board of the University of Chicago Medicine.

\section{Patient Population}

A retrospective chart review of medical, surgical, and imaging records was performed in all pediatric and adult patients who underwent spinal cord untethering at our institution between 2010 and 2015. One hundred twenty spinal cord untethering procedures were performed in 113 patients at our institution by 2 senior neurosurgeons; in 47 of those 113 patients preoperative prone MRI sequences were available for review. These patients underwent operation according to standard criteria that excluded prone imaging. Symptomatic outcome supported the decision to perform surgery, in that symptomatic patients uniformly improved. Those in whom operations for anatomical tethering (i.e., conus below L-3) were performed who were unable to describe symptoms (i.e., infants), or whose presentation was a cutaneous lesion without symptoms, did not worsen in any way. These patients were divided into 2 groups. Group 1 consisted of 25 patients with occult spinal dysraphism (most commonly fatty filum terminale) and the following criteria: tethered cord was suspected clinically, imaging demonstrated a conus below the inferior L-2 level and/or fatty filum terminale measuring $>2$ $\mathrm{mm}$ in thickness, no prior surgery, and surgical release of the tethered cord had been performed. Six patients whose imaging demonstrated a conus at or above the inferior endplate of L-2 with a fatty filum terminale measuring < $2 \mathrm{~mm}$ were not included in Group 1. Group 2 consisted of 16 patients with a history of prior surgery for cord untethering (etiologies included lipomyelomeningocele [10], myelomeningocele [1], fatty filum [2], lipoma [1], dermal sinus tract and lipoma [1], and diastematomyelia [1]); presentation with clinical findings suggestive of retethering; recent MRI with prone sequence; and subsequent reoperation for surgical repeat untethering.

Group 3 consisted of 30 consecutive, nonsurgically treated patients who were classified as normal controls for the purposes of this study. Lumbar spine MRI was initially requested in these patients for isolated nonspecific symptoms such as low-back pain, leg pain, scoliosis, or constipation. These patients had no or very low clinical suspicion of TCS, but nevertheless prone MRI sequences were included with the standard lumbar spine MRI study. All of these patients had unremarkable MRI findings aside from mild disc bulges, including normally positioned conus without thickened or fat-infiltrated filum, or other spinal lesions. These studies were predominantly requested by a primary care practitioner or the emergency department, and none of these patients required further neurological or neurosurgical evaluation at our institution.

\section{Evaluation With MRI}

Magnetic resonance imaging of the lumbar spine was performed in 71 patients, after obtaining informed consent, in the supine position and then in the prone position on a 1.5- or 3-T MR scanner. Standard supine lumbar spine imaging included sagittal and axial T1-weighted (TR 500-800 msec, TE 10-30 msec) and sagittal and axial T2-weighted (TR 3000-4000 msec, TE 90-120 msec) sequences obtained using a phased-array coil with 3- to 5 -mm-thick sections and field of view ranging from 14 to $30 \mathrm{~cm}^{2}$, depending on patient size. Prone images consisted of a sagittal T2-weighted sequence with similar parameters to the supine sagittal T2-weighted sequence.

The MR images were retrospectively evaluated by 2 independent reviewers who were blinded to the clinical findings. Reviewer training was supervised by a boardcertified neuroradiologist and included review of standard images to reduce interobserver variability. The position of the conus was assessed on the standard axial and sagittal supine sequences. The distance from the conus tip to the ventral dura mater was then measured in both the supine and prone sagittal T2-weighted sequences. Width of the dural sac was also measured at this level (Fig. 1).

\section{Data Analysis}

To determine the ventral motion of the conus, the distance in millimeters from the conus tip to the ventral dura in the supine and prone views was subtracted. To also allow comparison of ventral conus motion across a range of spinal canal diameters in our population, the percentage of spinal canal traversed by the conus was obtained in each patient by dividing the motion in millimeters by the entire canal width (anteroposterior diameter in the midline sagit- 


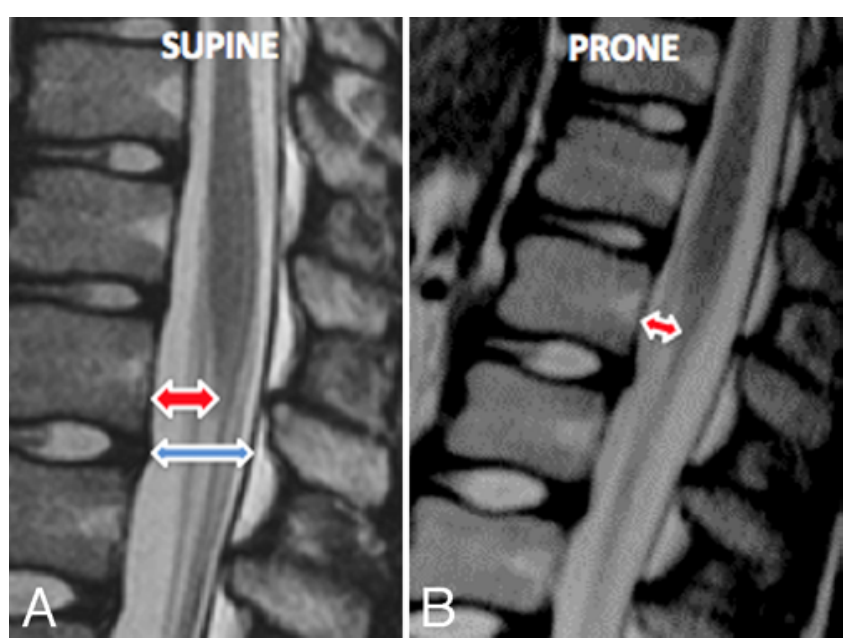

FIG. 1. Sagittal T2-weighted MR images with measurement technique. Distances from conus tip to ventral dura were measured in supine $\left(D_{s}\right)$ and prone $\left(D_{p}\right)$ views (red arrows) and subtracted. The difference was divided by the canal width (CW) (blue arrow) to give a percentage of movement, as shown in the following formula: \% movement $=\left[\left(D_{s}-D_{p}\right) /\right.$ $\mathrm{CW} \times \mathbf{1 0 0}$. Figure is available in color online only.

tal image, Fig. 1). An average of measurements from the 2 reviewers was then obtained.

For statistical purposes, ANOVA was conducted to determine if there was a statistically significant difference in the ventral motion of the conus between the 3 groups. Subsequent pairwise comparisons with Bonferroni correction were performed to determine which of the 3 groups had a statistically significant difference in ventral motion.

\section{Results}

Group 1 included 25 patients ( 9 males and 16 females), ages 1-33 years (mean age 6.0 years), who underwent initial lumbar surgery for release of tethered cord. The conus position ranged from L-1 to S-1. Six of these patients had a conus at or above the inferior L-2 endplate level (all of these patients had a thickened fatty filum measuring $>2$ $\mathrm{mm})$. The average conus tip movement in Group 1 was $0.5 \pm 0.5 \mathrm{~mm}$ (range $0-2.4 \mathrm{~mm}$ ), which gave a percentage of $3.7 \% \pm 3.9 \%$ (range $0 \%-16.3 \%$ ). In 14 patients with a conus at L-3 or below, the average conus movement was $0.5 \pm 0.3 \mathrm{~mm}$ (range $0.1-0.9 \mathrm{~mm}$ ), which gave a percentage of $3.8 \% \pm 2.5 \%$ (range $0.7 \%-9.6 \%$ ). The average canal diameter in Group 1 was $12.9 \mathrm{~mm}$.

Group 2 included 16 patients (7 males and 9 females), ages 9-58 years (mean age 20.9 years) who underwent repeat operation for clinical diagnosis of retethering. The conus position in this group ranged from L-1 to S-2. The average conus tip movement in this group was $0.4 \pm 0.7$ $\mathrm{mm}$ (range 0-2.6 mm), which gave a percentage of $2.2 \% \pm$ $3.7 \%$ (range 0\%-14.0\%). The average canal diameter was $18.5 \mathrm{~mm}$.

Group 3 included 30 patients (20 males and 10 females), ages 1-24 years (mean age 10.6 years), who were classified as normal controls for this study, as described in the Methods section. Conus position ranged from T-12 to L-2. The average conus tip movement in this group was $3.4 \pm$

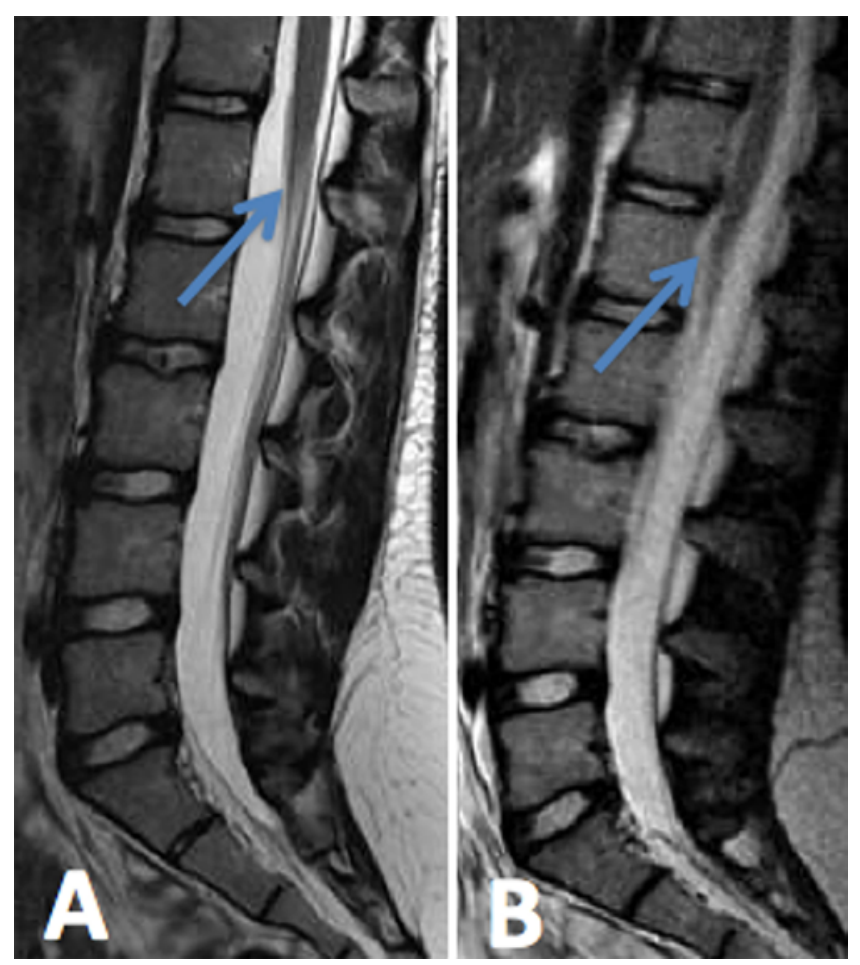

FIG. 2. Nontethered spinal cord. Sagittal T2-weighted supine (A) and prone $(\mathbf{B})$ images displaying the dorsal to ventral conus motion of a nontethered spinal cord. Arrows indicate conus position. Figure is available in color online only.

$1.3 \mathrm{~mm}$ (range 1.4-5.6 mm), which gave a percentage of $22.0 \% \pm 7.2 \%$ (range $10.5 \%-36.1 \%$ ) (Fig. 2). The average canal diameter was $15.3 \mathrm{~mm}$.

The ANOVA demonstrated a statistically significant difference in the ventral conus motion between the 3 groups $(\mathrm{p}<0.001)$. Subsequent pairwise comparison showed that Group 3 (nontethered controls) had greater and statistically significant ventral conus motion compared with Groups $1(\mathrm{p}<0.001)$ and $2(\mathrm{p}<0.001)$ after Bonferroni correction. No significant difference was detected in ventral conus motion between Group 1 (tethered) and Group 2 (retethered) ( $p=0.22$; Fig. 3).

Results from patients in Groups 1 and 2 were compared with Group 3 to determine an optimal threshold of ventral motion that could differentiate the surgically documented tethered and retethered cord groups from the normal controls. Ten percent canal width ventral motion was the cutoff value that provided optimal sensitivity and specificity jointly for detecting tethered cord. Thirty-eight of the 41 patients (23/25 in Group 1, 15/16 in Group 2) with surgically treated tethered cord had diminished motion on prone sequences, defined as $<10 \%$ canal width ventral motion (which correlated to a mean of $1.5 \mathrm{~mm}$ absolute distance) between supine and prone views. All 30 normal controls demonstrated $>10 \%$ canal width ventral motion. Using the $<10 \%$ canal width threshold, which was deemed optimal to suggest tethered or retethered cord, a sensitivity of $92.7 \%$ and a specificity of $100 \%$ were calculated (Table 1). Using an alternative $<15 \%$ canal width threshold, the sensitivity increased to $97.6 \%$ but the specificity decreased to 


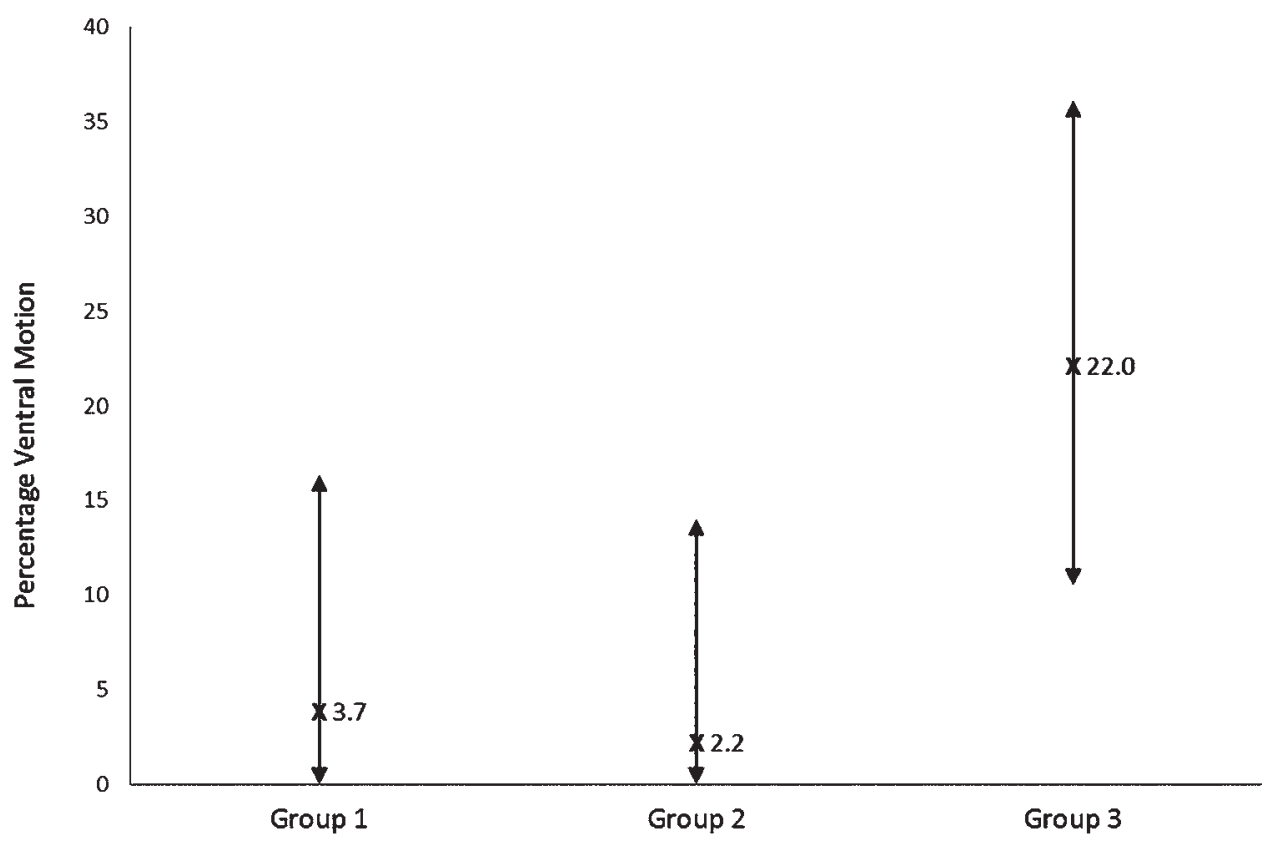

FIG. 3. Graph showing percentage of canal width. Ventral conus motion in the patients with tethered (Group 1), retethered (Group 2 ), and nontethered (Group 3) spinal cords. Arrows designate the sample range of conus movement. $X=$ mean conus movement.

80.0\% (Groups 1 and 2: 40/41 with < 15\% motion; Group 3: $6 / 30$ with $10 \%-15 \%$ motion).

Further analysis of only pediatric patients $(<21$ years of age) was also performed, which included 24 patients from Group 1, 12 patients from Group 2, and 28 patients from Group 3. We found that 22 of 24 pediatric patients in Group 1 with an initial diagnosis of tethered cord had $<10 \%$ canal width motion, and 11 of 12 patients in the retethered Group 2 had $<10 \%$ motion. All 28 normal pediatric controls had $>10 \%$ canal width motion. For pediatric patients, sensitivity and specificity were thereby calculated as $91.7 \%$ and $100 \%$, respectively. Using an alternate $<15 \%$ canal width threshold, the sensitivity increased to $97.2 \%$, whereas the specificity decreased to $78.7 \%$.

To assess interrater variability between the 2 readers, we calculated the intraclass correlation coefficient based on the 2-way random effects model. The intraclass correlation coefficient was $0.92(>0.75$ is considered excellent agreement). We also performed paired t-tests to compare the measurements from the 2 observers in the overall sample and individually in Groups 1,2, and 3, with resulting $p$ values of $0.86,0.45,0.66$, and 0.92 , respectively. All nonsignificant $\mathrm{p}$ values indicated that there was no evidence of bias (i.e., one rater consistently giving larger measurements than the other).

There were 6 additional patients with clinically suspected TCS (who were excluded from the 3 groups) who might be considered to have occult TCS. We obtained preoperative prone MRI that demonstrated a normal conus position at the inferior endplate of L-2 or above, and a thin fatty filum measuring $<2 \mathrm{~mm}$. These patients, however, had additional findings including conus syrinx and/ or neurogenic bladder, which prompted tethered cord release. Preoperative prone MRI in 3 of these patients demonstrated $0 \%$ ventral conus motion, $5 \%$ in a fourth, and approximately $20 \%$ motion in the remaining 2 patients. We excluded these 6 patients from Group 1 and the subsequent statistical analyses described above, due to the controversial nature of the occult TCS entity.

\section{Discussion}

In this study we evaluated the diagnostic utility of prone MRI in the diagnosis of tethered and retethered cord. Our population included primarily pediatric but also adult patients undergoing an initial untethering procedure or facing repeat untethering for recurrent TCS.

Lack of ossification of the posterior arch in infants or bony defect in patients with spinal dysraphism allows the use of ultrasound as a good screening modality for cord tethering. However, MRI has largely replaced ultrasound in the diagnostic evaluation of pediatric spinal dysraphism due to its superior ability to visualize and differentiate lesions involving the spinal canal and surrounding soft tissues. ${ }^{1,3-5,8,11}$ Cord motion on MRI has been measured by both the phase-contrast cine technique and by obtaining prone sequences. ${ }^{18}$ The normal spinal cord moves craniocaudally at approximately $1 \mathrm{~cm} / \mathrm{second}$ in opposition with CSF during systole and diastole, and dampening of this velocity by using phase-contrast MRI has been demonstrated in patients with tethered cord. ${ }^{2,11}$ This technique, however, requires careful calibration of the MR scanner to make accurate velocity measurements, and the current lack of a large series demonstrating its accuracy has further limited its use at most institutions. Studies with prone images have found ventral motion of the conus in patients with normal cords and often near-absent motion in TCS. ${ }^{21,22}$ Although less technically challenging than phase-contrast MRI, the addition of a prone sagittal T2-weighted sequence after repositioning an often anesthetized, pediatric patient adds 
TABLE 1. Number of patients with tethered versus nontethered (normal) spinal cord who exhibited ventral motion of the conus between supine and prone MRI

\begin{tabular}{ccc}
\hline Spinal Cord & $\begin{array}{r}\text { Diminished Movement } \\
(0 \% \text { or }<10 \%)\end{array}$ & $\begin{array}{c}\text { Movement } \\
(>10 \%)\end{array}$ \\
\hline Tethered (41) & 38 & 3 \\
\hline Nontethered $(30)$ & 0 & 30 \\
\hline
\end{tabular}

to the examination time (approximately 15 minutes in our experience). However, demonstrating reduced motion can provide further objective evidence of spinal cord tethering and may support the case for surgical intervention, especially in patients with a borderline normal conus level or in patients with recurrence of symptoms following treatment.

In examining all patients in the 3 groups who underwent prone MRI, we calculated a sensitivity of $93 \%$ and a specificity of $100 \%$ for diminished motion $(<10 \%$ canal width) on preoperative prone MRI to suggest a tethered cord. For the pediatric population, we calculated a similar sensitivity of $92 \%$ and a specificity of $100 \%$. Previously reported sensitivities and specificities for prone MRI in diagnosing tethered cord range from $62 \%$ to $67 \%$, slightly lower than the sensitivity of looking at the conus tip level $(69 \%-77 \%){ }^{18}$ In our sample, there was no threshold in degree of ventral conus motion, in terms of absolute distance or percentage of canal width, which perfectly separated the normal controls from the surgically documented tethered and retethered groups. Whereas all 30 of our patients in the normal control group exhibited $>10 \%$ motion, there were 3 patients in our tethered or retethered groups with $>10 \%$ motion (2/41 with $10 \%-15 \%$ motion, $1 / 41$ with $16 \%$ motion). Although a $15 \%$ cutoff value increased our sensitivity from $93 \%$ to $98 \%$, it decreased the specificity to $80 \%$. The drop in specificity was due to 6 patients in the normal control group in whom there was relatively little (10\%-14\%) motion, possibly related to small spinal canal or scoliosis, which limited motion (although this theory was not formally assessed in our study). A $10 \%$ cutoff value therefore provided optimal sensitivity and specificity jointly. The $10 \%$ canal width motion correlated to a mean of $1.5 \mathrm{~mm}$ absolute distance of ventral conus motion between supine and prone sequences; we caution however that using absolute distance as the threshold is probably less useful due to the developmental and age-related variations in spinal canal diameters. The percentage canal width may therefore be a more generalizable measurement for assessing cord tethering in the pediatric and adult populations.

Patients in Group 3, who were considered normal controls, demonstrated an average canal width motion of $22 \%$. This finding was lower than the $33 \%$ motion found by Witkamp et al. ${ }^{22}$ in their smaller, normal group of 15 patients. The mean age of our normal group was slightly younger (10.6 vs 15 years) than their described patient population, which might explain the difference in degree of motion. We should also acknowledge that although our normal controls presented to the hospital with nonspecific symptoms and a very low likelihood of cord tethering, these patients may not represent a truly "normal" popula- tion. Despite our smaller average percentage movement, Group 3 had conus movement that was greater and statistically significant when compared with Group $1(\mathrm{p}<0.001)$ or Group $2(\mathrm{p}<0.001)$, which is in agreement with prior work. ${ }^{22}$

During the data collection for our study we came across a particularly interesting group of 6 patients who had clinical findings highly suspicious for tethered cord but who demonstrated a normal conus position and a fatty filum with width $<2 \mathrm{~mm}$. These patients had findings such as neurogenic bladder and/or conus syrinx, which led to surgery for presumed tethered cord. Due to the controversial nature of the occult TCS entity, we chose to exclude these cases from our analysis. Nevertheless, in reviewing the preoperative prone images in these cases, 3 of the 6 patients demonstrated $0 \%$ motion and a fourth demonstrated only $5 \%$ motion. Because none of the patients in our normal control group demonstrated this degree of diminished motion, these findings lend support to the existence of patients with occult TCS, and suggest that prone images may have a special role in cases in which conventional imaging findings are equivocal (i.e., borderline low conus as an isolated finding, or the presence of fibrofatty filum at a width $<1-2$ $\mathrm{mm}$ with normal conus position) but in which prone imaging supports the case for surgical intervention (Fig. 4).

\section{Diagnosing Spinal Cord Retethering in Postoperative Patients}

Patients with TCS require follow-up for the possibility of symptom recurrence, the likelihood of which is dependent on the etiology. For example, in contrast to patients with fatty filum, patients with lipomyelomeningocele have

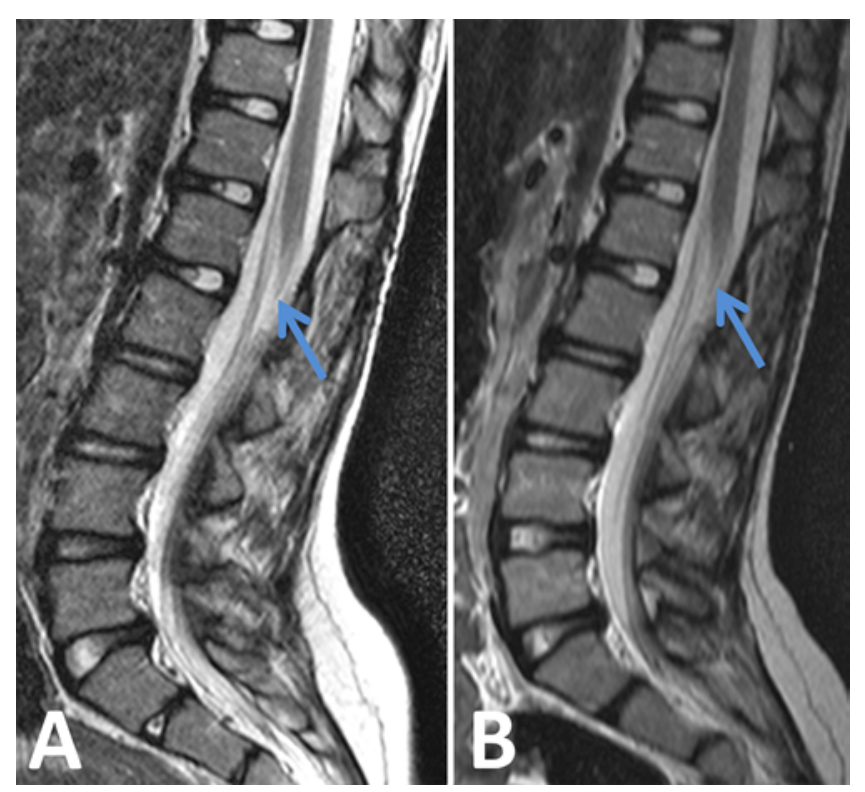

FIG. 4. Sagittal T2-weighted supine (A) and prone (B) images obtained in a patient with clinical suspicion of tethered cord. Conus was in normal position at L1-2, and neither fatty filum nor any other lesion within the lumbar spinal canal was evident on the conventional supine MRI sequences. Prone images demonstrate absence of ventral motion of the conus. Arrows designate the conus position. Figure is available in color online only. 
a high likelihood of retethering following surgical release. ., $, 16,17,19,20$ Prone MRI sequences may provide a noninvasive way to follow these patients postoperatively and can supplement supine MRI, which usually continues to demonstrate a low-lying conus despite surgical release. Group 2 consisted of patients in whom retethering occurred following previous surgical treatment; they had the lowest mean ventral conus motion among the groups, although this did not reach statistical significance when compared with the Group 1 patients without prior surgery $(p=0.22)$.

Further investigation is needed, particularly in patients with retethering. We have noticed anecdotally that even a few months after untethering, the prone imaging reveals minimal ventral motion even though significant intraoperative ventral movement of the conus and cauda equina nerve roots is observed immediately upon tethered cord release. This perplexing finding was encountered by Vernet et al. as well, ${ }^{21}$ and suggests that scarring and retethering may occur relatively early in some patients while they may not yet be symptomatic. In such patients, the addition of prone sequences on follow-up MRI studies may not be of added value because it would continue to show diminished motion; these patients may require further invasive testing (urodynamics, electromyography) to aid in the diagnosis. A separate control for Group 2 patients consisting of prone MRI in asymptomatic individuals with prior tethered cord release may perhaps better assess the rate of "false-positive" prone MRI studies in the postoperative patients, and can be considered a limitation of this study. Future investigations can also assess patients for a possible correlation of degrees of diminished ventral motion and clinical impairment.

\section{Conclusions}

In the present analysis, consisting of a larger sample size than previously available in the literature, lack of ventral conus motion on prone MRI is found to be sensitive and specific in suggesting tethered cord, and we believe these sequences have a role as supportive evidence in the diagnosis of tethered and retethered spinal cord. We also suggest $10 \%$ canal width motion as a threshold that can separate the tethered and the nontethered groups. Interestingly, there was a small overlap in our sample, with 3 of 41 patients with TCS exhibiting relatively preserved motion $(10 \%-16 \%)$, and 6 of 30 patients in the normal control group exhibiting relatively little motion (10\%-14\%), possibly due to a relatively small spinal canal or scoliosis. Future investigations will assess ventral motion on serial MRI studies on patients after untethering, and will also assess for a possible inverse correlation of degree of ventral motion to degree of clinical impairment.

\section{Acknowledgments}

We acknowledge Kristen Wroblewski, MS, for reviewing the statistical analyses contained in this study.

\section{References}

1. Brunberg JA, Latchaw RE, Kanal E, Burk DL Jr, Albright L: Magnetic resonance imaging of spinal dysraphism. Radiol Clin North Am 26:181-205, 1988
2. Brunelle F, Sebag G, Baraton J, Carteret M, Martinat P, Pierre-Kahn A: Lumbar spinal cord motion measurement with phase-contrast MR imaging in normal children and in children with spinal lipomas. Pediatr Radiol 26:265-270, 1996

3. Byrd SE, Darling CF, McLone DG, Tomita T: MR imaging of the pediatric spine. Magn Reson Imaging Clin N Am 4:797-833, 1996

4. Chern JJ, Aksut B, Kirkman JL, Shoja MM, Tubbs RS, Royal SA, et al: The accuracy of abnormal lumbar sonography findings in detecting occult spinal dysraphism: a comparison with magnetic resonance imaging. J Neurosurg Pediatr 10:150-153, 2012

5. Hall WA, Albright AL, Brunberg JA: Diagnosis of tethered cords by magnetic resonance imaging. Surg Neurol 30:6064,1988

6. Herman JM, McLone DG, Storrs BB, Dauser RC: Analysis of 153 patients with myelomeningocele or spinal lipoma reoperated upon for a tethered cord. Presentation, management and outcome. Pediatr Neurosurg 19:243-249, 1993

7. Klekamp J: Tethered cord syndrome in adults. J Neurosurg Spine 15:258-270, 2011

8. Kuharik MA, Edwards MK, Grossman CB: Magnetic resonance evaluation of pediatric spinal dysraphism. Pediatr Neurosci 12:213-218, 1985-1986

9. Lagae L, Verpoorten C, Casaer P, Vereecken R, Fabry G, Plets $C$ : Conservative versus neurosurgical treatment of tethered cord patients. Z Kinderchir 45 (Suppl 1):16-17, 1990

10. Lavallée LT, Leonard MP, Dubois C, Guerra LA: Urodynamic testing-is it a useful tool in the management of children with cutaneous stigmata of occult spinal dysraphism? J Urol 189:678-683, 2013

11. Levy LM, Di Chiro G, McCullough DC, Dwyer AJ, Johnson DL, Yang SSL: Fixed spinal cord: diagnosis with MR imaging. Radiology 169:773-778, 1988

12. Lew SM, Kothbauer KF: Tethered cord syndrome: an updated review. Pediatr Neurosurg 43:236-248, 2007

13. Nakanishi K, Tanaka N, Kamei N, Nakamae T, Izumi B, Ohta R, et al: Use of prone position magnetic resonance imaging for detecting the terminal filum in patients with occult tethered cord syndrome. J Neurosurg Spine 18:76-84, 2013

14. Ostling LR, Bierbrauer KS, Kuntz C IV: Outcome, reoperation, and complications in 99 consecutive children operated for tight or fatty filum. World Neurosurg 77:187-191, 2012

15. Roy MW, Gilmore R, Walsh JW: Evaluation of children and young adults with tethered spinal cord syndrome. Utility of spinal and scalp recorded somatosensory evoked potentials. Surg Neurol 26:241-248, 1986

16. Sakamoto H, Hakuba A, Fujitani K, Nishimura S: Surgical treatment of the retethered spinal cord after repair of lipomyelomeningocele. J Neurosurg 74:709-714, 1991

17. Samuels R, McGirt MJ, Attenello FJ, Garcés Ambrossi GL, Singh N, Solakoglu C, et al: Incidence of symptomatic retethering after surgical management of pediatric tethered cord syndrome with or without duraplasty. Childs Nerv Syst 25:1085-1089, 2009

18. Singh S, Kline-Fath B, Bierbrauer K, Racadio JM, Salisbury S, Macaluso M, et al: Comparison of standard, prone and cine MRI in the evaluation of tethered cord. Pediatr Radiol 42:685-691, 2012

19. Tamaki N, Shirataki K, Kojima N, Shouse Y, Matsumoto S: Tethered cord syndrome of delayed onset following repair of myelomeningocele. J Neurosurg 69:393-398, 1988

20. Vassilyadi M, Tataryn Z, Merziotis M: Retethering in children after sectioning of the filum terminale. Pediatr Neurosurg 48:335-341, 2012

21. Vernet O, O'Gorman AM, Farmer JP, McPhillips M, Montes JL: Use of the prone position in the MRI evaluation of spinal cord retethering. Pediatr Neurosurg 25:286-294, 1996 
22. Witkamp TD, Vandertop WP, Beek FJA, Notermans NC, Gooskens RHJM, van Waes PFGM: Medullary cone movement in subjects with a normal spinal cord and in patients with a tethered spinal cord. Radiology 220:208-212, 2001

23. Yong RL, Habrock-Bach T, Vaughan M, Kestle JR, Steinbok P: Symptomatic retethering of the spinal cord after section of a tight filum terminale. Neurosurgery 68:1594-1602, 2011

\section{Disclosures}

The authors report no conflict of interest concerning the materials or methods used in this study or the findings specified in this paper.

\section{Author Contributions}

Conception and design: Ali, Stamates, Frim, Katzman. Acquisi- tion of data: Ali, Stamates, Frim. Analysis and interpretation of data: Ali, Stamates, Frim. Drafting the article: Ali, Stamates. Critically revising the article: all authors. Reviewed submitted version of manuscript: all authors. Approved the final version of the manuscript on behalf of all authors: Ali. Statistical analysis: Ali, Stamates. Administrative/technical/material support: Ali, Stamates, Frim. Study supervision: Ali, Frim.

\section{Supplemental Information}

\section{Previous Presentations}

Presented in poster form at the AANS annual meeting (Chicago, IL) in 2016 and at the American Society of Neuroradiology annual meeting (Washington, DC) in 2016.

\section{Correspondence}

Saad Ali, Department of Radiology, Section of Neuroradiology, University of Chicago Medical Center, 5841 S Maryland Ave., MC2026, Chicago, IL 60637. email: saadali@uchicago.edu. 